\title{
Unlikely Bedfellows? Collingwood, Carnap and the internal/external distinction ${ }^{1}$
}

Abstract. Idealism is often associated with the kind of metaphysical system building which was successfully disposed of by logical positivism. As Hume's fork was intended to deliver a serious blow to Leibnizian metaphysics so logical positivism invoked the verificationist principle against the reawakening of metaphysics, in the tradition of German and British idealism. In the light of this one might reasonably wonder what Carnap's pragmatism could possibly have in common with Collingwood's idealism. After all, Carnap is often seen as a champion of the logical positivist's critique of metaphysics, whilst Collingwood is renowned for his defence of the possibility of metaphysics against the attack to which Ayer subjected it. The answer is that they have more in common than one might suspect and that, once the relevant qualifications are made, there is as much convergence as there is contestation between Carnapian pragmatism and Collingwoodian idealism.

\section{Introduction}

It is sometimes said that when it comes to metaphysical questions philosophers exhibit two casts of mind: they are either curious or quizzical. Curious philosophers believe metaphysical questions to have substantive answers which it is the task of the philosopher to discover from the proverbial armchair. Metaphysical questions, curious philosophers would concede, are hard to answer but they are not impossible to answer. Quizzical philosophers, on the other hand, do not believe metaphysical questions to have genuine answers. Metaphysical questions are not simply hard to answer; they are unanswerable. Metaphysical questions, so quizzical philosophers argue, are unlike questions which arise within the first order sciences, questions such as "how many fish are there in the sea?" or "who is responsible for the Lockerbie disaster?" The answers to these questions may not be easy to come by, but the questions themselves are in principle answerable. Unlike such hard but answerable questions, metaphysical ones are unanswerable because they arise from conceptual confusion.

The distinction between curiosity and quizzicality was introduced by Yablo and Gallois (Yablo and Gallois 1998) who identified the attitude of curiosity with the "analytic movement's official attitude", the one which has generally prevailed "after a period of ordinary-language-inspired quizzicality" (Yablo and Gallois 1998: 231). Though originally introduced to distinguish between different phases within the analytic tradition, Yablo and Gallois' distinction could be easily adapted to capture the relation between idealists and pragmatists. Hegel, the prototypical idealist, is often (rightly or wrongly) regarded as the arch-rationalist metaphysician who sought to restore confidence in our ability to know the ultimate structures of reality after a period of misguided Kantian humility. ${ }^{2}$ Pragmatists, on the other hand, have tended to be suspicious of the notion of metaphysical truth. Rorty explicitly claimed that "The pragmatist... does not think of himself as any kind of metaphysician" (Rorty 1982: xxviii) and more recently Huw Price has clearly allied himself with the deflationary approach favoured by philosophers of a quizzical cast of mind (Price 2009). Yet, whilst

\footnotetext{
${ }^{1}$ I would like to thank one of the anonymous referees of this paper for their helpful suggestions.

${ }^{2}$ The reading of Hegel as the prototypical arch-rationalist metaphysician has been questioned by scholars such as Robert Pippin (Pippin 1989) and Terry Pinkard (Pinkard 1994) who read Hegel as radicalizing Kant's Copernican turn and eliminating the sceptical remainder in Kant without returning to a form of pre-critical metaphysics.
} 
the distinction between the attitude of curiosity and of quizzicality would appear to be tailor-made to capture the relation between idealists and pragmatists, reality is always more complex than it looks at first glance, for the devil, as the saying goes, is always in the detail. In the following I will consider the strange case of an idealist and a pragmatist who agree on much more than one might otherwise expect in the light of their professed philosophical allegiances. In fact, once one excavates a little one finds more convergence than one might expect across the ideological divide which allegedly separates them.

In the following I begin by outlining Carnap's internal/external distinction and argue that Carnap's identification of metaphysical questions with pseudo-questions concerning the truth/falsity of linguistic frameworks bears remarkable similarities to Collingwood's claim that there is no such thing as presuppositionless knowledge and that traditional metaphysics, understood as a science of pure being, is not a possible enterprise. I then suggest that Carnap's introduction of the distinction between internal and external questions and Collingwood's introduction of the distinction between propositions and presuppositions enables them to evade the self-refutation objection that is often raised against logical positivism. I conclude by arguing that whilst Collingwood and Carnap belong to different philosophical traditions they share a quizzical attitude towards philosophical questions and that we gain a deeper understanding of the nature of Collingwood's metaontology if we read it through the lens of Carnap's distinction between internal and external questions.

\section{Carnap on internal and external questions}

In "Empiricism, Semantics and Ontology" Carnap distinguished between ontological or existence questions which arise within a linguistic framework and ontological or existence questions applied to linguistic frameworks (Carnap 1950). He argued that ontological questions which arise within a framework are legitimate internal questions, whereas questions about the existence or reality of the framework itself are external and illegitimate. Carnap's distinction between legitimate internal questions and illegitimate external ones is underwritten by the view that there are no frameworkindependent ontological viewpoints available to the metaphysician and thus that existential questions are unanswerable independently of the framework within which they arise. Consider, for example, the question "How many odd numbers are there between 0 and 100 ?" This is an internal question which can be answered by referring to the rules of the "number" framework. Now consider the question "Are there numbers?" or "Do numbers exist?" This question may be construed either as an internal or as an external question. If construed as an internal question it will have a trivially true answer. Given that "100 is a number" (and this is analytic), that "There are numbers" follows from the analytic statement "100 is a number". No one who asks the question as an internal question expects anything other than a trivially true affirmative reply. Yet, Carnap says, philosophers take the answer to this question to be neither trivially true nor necessarily affirmative. This indicates that they construe the question in a different way, that is, not as an internal question with a trivially true answer but as an external question with genuine cognitive content that could potentially be answered in the negative. The question "Are there Numbers", as asked by philosophers, is about the reality of the number framework; it is about whether or not numbers exist independently of the adoption of the framework or whether the framework itself is real. Carnap objects that, construed in 
this way, the question cannot be given a cognitive interpretation and is thus a pseudo-question to which there is no meaningful answer. Frameworks, for Carnap, can be of a logical or of a factual nature. The "number" framework is of a logical nature. The "thing" framework (the spatiotemporally ordered system of observable objects) on the other hand is a framework of a factual nature. In a factual framework, to recognize something as real is "to incorporate it into a framework of things at a particular space-time position" and questions about such entities are answered by empirical investigation. Within this framework questions such as "is the cat on the mat?" will be answered empirically. On the other hand, the question "Do spatio-temporal entities exist?" or "Are spatio-temporal entities real?" is always answered affirmatively, just as the proposition "There exist numbers" or "Numbers are real" is entailed by the commitments to some contingently true existential claim such as "There is a cat on the mat". But when asked as an external question, as a question about the reality of the thing framework, the question "Do spatio-temporal entities exist?" is an unanswerable question just like the one concerning the reality of the "number" framework. Carnap claims that external questions are raised "neither by the man in the street nor by scientists, but only by philosophers. Realists give an affirmative answer, subjective idealists a negative one, and the controversy goes on for centuries without ever being solved." (Carnap [1950] 2011: 251)) The problem that metaphysicians take themselves to be addressing "cannot be solved because it is framed in the wrong way. To be real in the scientific sense means to be an element of the system; hence this concept cannot be meaningfully applied to the system itself." (Carnap [1950] 2011: 251) Metaphysical questions such as "Do numbers exist?" have no cognitive content, and thus unlike questions such as "How many odd numbers are there between 0 and 100?" they are unanswerable pseudo-questions.

Carnap concedes that questions concerning the adoption of frameworks may be legitimately asked but only if they are construed not as questions about the truth or falsity of the framework but as pragmatic questions about their utility. One of the key goals of Carnap's "Empiricism, Semantics and Ontology" is to allow for talk of abstract entities within empiricist epistemology without going "back to a metaphysical ontology of the Platonic kind" (Carnap [1950] 2011:249). How can empiricists allow for universals, properties, relations etc.? The introduction of frameworks allows them to do so without committing themselves to a Platonic ontology by switching from one discourse to another when such switching is pragmatically useful:

Empiricists are in general rather suspicious with respect to any kind of abstract entities like properties, classes, relations, numbers, propositions, etc. They usually feel much more in sympathy with nominalists than with realists. As far as possible they try to avoid any references to abstract entities and to restrict themselves to what is sometimes called a nominalistic language, i.e., one not containing such references. However, within certain scientific contexts it seems hardly possible to avoid them. In the case of mathematics, some empiricists try to find a way out by treating the whole of mathematics as a mere calculus, a formal system for which no interpretation is given or can be given. Accordingly the mathematician is said to be speaking not about numbers, function, and infinite classes, but merely about meaningless symbols and formulas manipulated according to given formal rules. In physics it is more difficult to shun the suspected entities... A physicist who is suspicious of abstract entities may perhaps try to declare a certain part of the language of physics as uninterpreted and uninterpretable, 
that part which refers to real numbers as space-time coordinates or as values of physical magnitudes, to functions, limits, etc. More probably he will just speak about all these things like anybody else but with an uneasy conscience, like a man who in his everyday life does with qualms many things which are not in accord with the high moral principles he professes on Sundays." (Carnap [1950] 2011: 249)

Carnap's internal/external distinction has a number of important implications. It implies, first, that our ontological commitments are dependent upon the adoption of a linguistic framework. Second, given that there is a plurality of frameworks, we ought to be ontological pluralists. Ontological pluralism is simply the result of framework pluralism combined with view that there is no framework-independent ontological viewpoint. Third, and crucially, the internal/external distinction alters the status of the principle of verification. For once the internal/external distinction is in place, the principle of verification becomes an internal criterion of meaning. Instead of stating that sentences which are empirically unverifiable are meaningless simpliciter, it states that they are meaningless from the standpoint of an empiricist language/framework. The standard version of logical empiricism which was advocated by the members of the Vienna circle, including the earlier Carnap, claimed that the principle of verification simply spelled out the conditions for the meaningfulness of propositions without any further qualifications: if propositions are neither empirically verifiable nor analytic they must therefore be meaningless gibberish. ${ }^{3}$ Since Carnap's introduction of the internal/external distinction inscribes the principle of verification within a "factual/thing" framework, it entails not that metaphysical propositions are meaningless (as the standard version of the principle of verification states), but that they are meaningless from an empiricist standpoint. As a result, the main legacy of the internal/external distinction is that metaphysical questions are confused and unanswerable not simply because they are empirically unverifiable, but because they expect the kind of answers that can be given only once a framework is in place. Carnap (at least the Carnap of "Empiricism, Semantics and Ontology") can thus be seen as a champion of a certain kind of metaphysical deflationism according to which traditional metaphysical questions are confused because they seek answers to external questions. On this view, the opposing sides in the ontological disputes such as those between realists and nominalists about

\footnotetext{
${ }^{3}$ Richard Creath (2011) argues that Carnap had broken away from the standard version of logical positivism with the introduction of the Principle of Tolerance as early as 1935 . Once the Principle of Tolerance is introduced, "each of the various versions of empiricism (including some sort of verificationism) is best understood as a proposal for structuring the language of science. Before tolerance, both empiricism and verificationism are announced as if they are simply correct. Correspondingly, what Carnap called metaphysics is then treated as though it is, as a matter of brute fact, unintelligible. But what is announced thus dogmatically can be rejected equally dogmatically. Once tolerance is in place, alternative philosophic positions, including metaphysical ones, are construed as alternative proposals for structuring the language of science." (section 4.1: Empiricism, Verificationism and Anti-metaphysics.) For an account of authors who read Carnap as a champion of logical positivism see Carus 1999. For a rejection of the standard reading of Carnap as a logical positivist see Friedman 2007 and 2009a. The interpretation of Carnap given here is close to Friedman's neoKantian reading but it is no way uncontroversial since many still see Carnap's philosophical programme as a continuation of traditional empiricism. For a discussion of empiricist and neo-Kantian readings see Wagner (2009).
} 
universals simply fail to recognize that ontological commitments are framework-dependent. Once it is acknowledged that ontological questions are internal questions, the dispute is deflated. ${ }^{4}$

The metaphysical deflationism which arises from Carnap's introduction of the internal/external distinction bears some unexpected and yet remarkable similarities to Collingwood's critique of traditional metaphysics as a presuppositionless science of pure being in An Essay on Metaphysics. (Collingwood: 1940) As we shall see Collingwood, like Carnap, denied that that there is any such thing as knowledge of being qua being and accepts the ontological pluralism which ensues from framework pluralism. Even though Collingwood does not share the more overtly therapeutic implications which are often associated with Carnapian deflationism, since he argues not just against traditional metaphysics but also for a metaphysics of a different kind, he clearly endorses the Carnapian view that frameworks may not be tested for truth and falsity in the same way as elements internal to a framework can.

\section{Collingwood on absolute presuppositions}

Collingwood shared Carnap's view that it is not possible to give any cognitive content to the external questions asked by traditional metaphysicians. In so far as traditional metaphysics investigates what there is or exists independently of any presupposition, it endeavours to be a science of "pure being" which yields unmediated knowledge of reality, what Kant would have called reality as it is in itself. Collingwood argues that it is a mistake to think of presuppositionless knowledge as a kind of knowledge because knowledge claims can be made only against the background of certain presuppositions which determine what count as true or false answers to the questions we ask. Since there can be no such thing as presuppositionless knowledge, metaphysics as traditionally construed has no possible object of enquiry. What then is the subject matter of philosophy? Does it follow that, since metaphysics has no subject matter, all philosophical problems are pseudo-problems and philosophy has no genuine subject matter of its own? Carnap argued that since questions which seek for framework-independent answers have no cognitive content there is no such thing as what is regarded as the traditional subject matter of philosophical enquiry. Collingwood by contrast argues that frameworks are the very object of investigation of metaphysical analysis because philosophers are concerned with uncovering the higher level principles which govern forms of enquiry. The philosopher, however, is not concerned with the truth of such principles but rather with the logical role that they play in making forms of enquiries possible. To explain this we need to consider Collingwood's account of metaphysics as a science of presuppositions.

Collingwood distinguishes between presuppositions and propositions. ${ }^{5}$ Whether a statement is a presupposition or a proposition, for Collingwood, is determined by the role that it plays in the asking and answering of questions. A statement is a presupposition in so far as it is an assumption from

\footnotetext{
${ }^{4}$ In the contemporary metaontological debate Carnap is often invoked as the figure behind the view that apparently intractable philosophical disagreements such as those between endurantists and perdurantists, mereologists and anti-mereologists and between the scientific and the manifest image are the result of a dogmatic commitment to a framework. See the essays by Hirsch, Price and Thomasson in Chalmers 2009. For Carnap's influence on the contemporary metaontological debate see Eklund, M. (2013 and forthcoming).

${ }^{5}$ See Collingwood 1940, 1998 pp. 21-33.
} 
which questions arise. A statement is a proposition if is offered in answer to a question. In this respect a statement may be compared to a football player who will be classed as a defender if his role is to keep the ball away from the goal keeper or as a forward if his role is to score goals when his playmates pass him the ball. Much as what defines a player on the football pitch is the role he is assigned in the game (to attack or to defend), so what determines whether a statement is a proposition or a presupposition is not its propositional content but the role the statement plays in what Collingwood calls the "logic of question and answer". Thus for example the statement "There is beer in the fridge" could be offered in answer to the question "Is there anything to drink?" In this case it would be a proposition because its role would be to answer a question. But if it were an assumption giving rise to the question "Could you fetch the beer from the fridge, please?", then it would be not a proposition but a presupposition, much as the player who is moved from attack to defence would no longer be a forward.

Collingwood refers to the power of presuppositions to give rise to questions as their "logical efficacy" and argues that the truth or falsity of presuppositions is irrelevant to the power they have to give rise to questions. The question "Could you fetch the beer from the fridge?" would arise from the presupposition that there is beer in the fridge, even if there were in fact none. The statement "There is beer in the fridge" thus has logical efficacy not in so far as it is true or false but in so far as it is presupposed. We understand the questions we are being asked in so far as we understand what presuppositions give rise to them whilst we fail to understand questions if we do not understand the presuppositions from which they arise. Thus we understand a child who asks whether Rudolph ate the carrot which had been left for him, not because we believe that Santa exists and travels round the globe on Christmas night to deliver presents to well-behaved children, but because we understand that if one presupposes Santa to exist, then one may legitimately ask if his reindeer stopped to replenish itself with the food that one has left him.

Propositions, unlike presuppositions, have a truth value since questions may be answered truly or falsely and it is the role of propositions to answer questions. Presuppositions, by contrast, Collingwood argues, have no truth value because their job, qua presuppositions, is to give rise to questions. And they give rise to questions not in so far as they are true (or false) but in so far as they are presupposed. "Presupposition" and "proposition" are therefore technical terms and whether a statement is a proposition or a presupposition is determined by the role that it plays in the logic of question and answer, much as whether a football player is a defender or a forward is determined by the role he plays in the game of football. Some presuppositions, Collingwood claims, have a very special status. They are absolute rather than relative. A presupposition is absolute if it determines the kind of questions that can be asked within a certain form of enquiry. An example of an absolute presupposition is the sense of causation which is at work in what Collingwood calls the practical sciences of nature, sciences such as medicine and engineering. No self-respecting engineer or doctor could practice without presupposing a conception of causation as a handle that can be turned to produce or prevent the desired effects because to engage in these practices requires presupposing that nature can be manipulated to achieve human purposes, wind to generate electricity, vaccines to prevent illness etc. In the practical sciences of nature a cause is "an event by producing or preventing which one can produce or prevent that whose cause it is said to be."(Collingwood 1940: 296-7) This presupposition is absolute because it cannot be forsaken without undermining the form of inquiry it makes possible. Absolute presuppositions may therefore be compared to the rules 
which govern games such as football. Whilst a football player may be moved from attack to defence, and changing his role in the game does not alter the kind of the game that is being played, a football player cannot engage the ball with his hands without committing a foul. Similarly, the absolute presuppositions which govern one form of enquiry cannot be disregarded without changing the subject, much as directing the ball with one's hands would turn a game of football into one of netball. It is not so much that a player cannot choose to direct the ball with his hands rather than his feet but rather that if he does then he is no longer engaging the ball within the game of football.

There are many presuppositions which will be made by the practitioners of a form of enquiry that are not absolute. A doctor may presuppose that "smoking causes lung cancer" and, on this basis, demand of his patient that she should stop smoking. The presupposition that "smoking causes lung cancer" is not absolute, and could, potentially, be offered as an answer to the question, "What is the cause of lung cancer?" In this case it will have a truth-value which can be ascertained empirically. Whilst some statements can have a double role (as presuppositions or as presuppositions), some presuppositions have only one role, that of giving rise to questions, and consequently they can never be proffered as genuine answers to (non-rhetorical) questions. Thus for example the absolute presupposition that a cause "is an event by producing or preventing which one can produce or prevent that whose cause it is said to be" cannot genuinely be questioned by the practitioners of those forms of enquiry which the presupposition underwrites. No self-respecting doctor, car mechanic or engineer can truly question whether they can intervene in nature to improve the human lot. Doctors may question whether some of their relative presuppositions are true. They may question whether colds really are caused by viruses or whether smoking really causes lung cancer, but they cannot genuinely entertain the possibility that there really are no such things as causes (on the handle conception) without jeopardizing the form of enquiry in which they are engaged. This is not to say that absolute presuppositions can never be questioned, but rather that the question "Are there causes (on the handle conception)?" or "Do causes (on the handle conception) exist?" will be deemed to be rhetorical and necessarily answered in the affirmative by the practitioners whose form of enquiry is made possible by that presupposition. For if the bite of a mosquito is the preventable cause of malaria or if wind can be channelled to produce electricity, then it follows from this that it is possible to prevent or produce certain natural events with a view to curing illnesses or improving the human lot.

There are some differences between Carnapian frameworks and Collingwood's absolute presuppositions. Frameworks, for Carnap, are essentially logical or non-logical calculi, i.e. systems of axioms and inference rules expressed in a suitable formal language whilst for Collingwood absolute presuppositions structure our yet to be analysed modes of inquiry. But there are also clear parallels between Collingwood's account of absolute presuppositions and Carnap's views concerning the relation between internal and external questions. For Carnap, as we saw, when general existential questions about the framework are asked from within the framework they elicit affirmative answers which are deemed to be trivially true. For within the "numbers" framework the proposition "numbers exist" or "numbers are real" is analytically entailed by the claim that "100 is a number". Analogously that "there exist material objects" is analytically entailed by the claim "there is a (spatio-temporally located) cat on the (spatio-temporally located) mat". What both Collingwood and Carnap disallow is that questions concerning linguistic frameworks or in Collingwood's case, absolute presuppositions, may be legitimately asked as external questions demanding non-trivial, 
substantively true or false answers about the framework itself. Similarly Collingwood rejects the view that external ontological questions about the existence of absolute presuppositions have genuine answers by saying that metaphysics traditionally conceived as a science of pure being is not a possible enterprise because there is no such thing as presuppositionless knowledge of what exists. Being can only be known given certain presuppositions, such as those made by historians, natural scientists or within the practical sciences of nature. He agrees with Carnap that there is no framework-independent ontological commitment since existence questions can be meaningfully answered within the absolute presuppositions which govern different forms of enquiry. He too is an ontological pluralist and his ontological pluralism is a straightforward implication of his commitment to his pluralism concerning absolute presuppositions, taken together with the claim that there is no such thing as presuppositionless knowledge.

Collingwood's ontological pluralism is best gleaned from his discussion of the term "cause" in An Essay on Metaphysics, where he tells us that the term "cause" has different meanings in different explanatory contexts. Thus while the sense of causation operative within the practical sciences of nature is the so-called "handle" conception, the theoretical sciences of nature, such as physics, absolutely presuppose a sense of causation that is unconditional. A cause, in the theoretical sciences of nature is an unconditional antecedent condition such that if the cause occurs the effect will follow. ${ }^{6}$ Causal answers, according to Collingwood, have to be carefully matched to the kind of whyquestions that are being asked. When they are mismatched the question that is being asked simply remains unanswered. As Collingwood puts it:

if my car fails to climb up a steep hill, and I wonder why, I shall not consider my problem solved by a passer-by who tells me that the top of the hill is farther away from the earth's center than its bottom, and that consequently more power is needed to take the car uphill than to take her along the level. All this is quite true; what the passerby has described is one of the conditions which together form... what I call the cause in sense III... But suppose an AA man comes along, opens the bonnet, holds up a loose high-tension lead and says: "Look here, sir, you're running on three cylinders". My problem is now solved... If I had been a person who could flatten out hills by stamping on them the passer-by would have been right in calling my attention to the hill as the cause of the stoppage; not because the hill was a hill but because I was able to flatten it out. (Collingwood 1940: 302-3)

The passerby in Collingwood's example is a physicist who operates not with the handle conception of causation familiar to doctors, engineers and car mechanics alike but with the sense of causation operative in the theoretical sciences of nature where the notion of explanation abstracts from any human interest in harnessing nature. Different explanatory contexts call for different senses of causation. In what Collingwood calls the historical sciences the concept of causation is not efficient because what the historian seeks to uncover is the goal or point of action and uncovering this requires appealing to a form of explanation that is teleological rather than nomological. A detailed discussion of the notion of explanation which is at work in what Collingwood refers to as the

\footnotetext{
${ }^{6}$ For Collingwood's account of the different senses of the term "cause", see Collingwood [1940] 1998 p. $285 \mathrm{ff}$.
} 
historical sciences and how such explanations differ from those at work in the natural sciences cannot be provided in this context. ${ }^{7}$ But Collingwood's point concerning the need to match causal/becausal answers to the right kind of why-question entails that the questioner's curiosity will not be satisfied unless that is done. ${ }^{8}$

Collingwood explicitly developed his account of absolute presuppositions against the principle of verification defended by Ayer in Language, Truth and Logic. (Ayer 1936) Updating the Humean fork for the twentieth century, Ayer argued that propositions which are not empirically verifiable are meaningless (unless they are tautologies). Collingwood replied that absolute presuppositions are not rendered meaningless by the verification principle because they are not propositions. Since they are not propositions, the notion of truth and falsity does not apply to them. Contrary to what Ayer argues in Language Truth and Logic, there are statements which are meaningful even if they are not verifiable (empirically or analytically). To assert that absolute presuppositions are meaningless on the grounds that they are unverifiable is tantamount to mistaking their role in the logic of question and answer. And it is from this failure to understand the role that presuppositions play in the logic of question and answer that the misplaced demand that they should be verified arises.

Collingwood's critique of traditional metaphysics is thus rather different from the standard logical positivist critique of metaphysics according to which claims which are verifiable neither empirically nor analytically are meaningless gibberish. From Collingwood's perspective, the statement 'causes exist' is not meaningless because it is not empirically verifiable, as Ayer claimed. It is meaningless rather because the attempt to verify absolute presuppositions by assigning them a truth value would be as nonsensical as the attempt to answer the question "how long is the standard metre?" with anything other than an innocent, trivially true answer to an internal question: "It is 100 centimetres long." While it is true to say that Collingwood does share with the logical positivists the view that metaphysics, as traditionally conceived, is not a possible enterprise, his reasons for saying this are

\footnotetext{
${ }^{7}$ Collingwood was invoked as an ally in the debate against methodological unity in the sciences by W.H. Dray who reworked Collingwood's claim that there are different senses of causation at work in different explanatory contexts by arguing that the logical structure of historical explanation is rational not nomological. See for example Dray 1957 and 1963. Collingwood's defence of autonomy of the human sciences was informed by his conception of metaphysics as a science of absolute presuppositions and was overshadowed by the return of a more robust conception of the nature of metaphysical enquiry. See D'Oro 2012.

${ }^{8}$ Collingwood is often regarded as a historicist or historical relativist who takes absolute presuppositions to be relative to groups of people in certain periods of history. On the reading given here Collingwood is a contextualist who takes absolute presuppositions to be relative to forms or modes of inquiries rather than to time and place. In this respect Collingwood's notion of absolute presuppositions is closely related to Michael Friedman's discussion of relativized a priori principles and their meaning-constitutive role in the sciences (Friedman 2009b). For Friedman such a priori principles are both "genuinely historical and properly transcendental": they are necessary not because they are universally valid but in virtue of their constitutive role. Equally for Collingwood absolute presuppositions are not universally valid: different forms of inquiry have different absolute presuppositions. Their applicability however is limited not to time and place but to the forms of enquiry which they make possible. Thus although absolute presuppositions are not strictly universal they are nonetheless necessary in virtue of the role they play in determining the kind of evidence that can be given in answer to the questions which they make possible. I have defended this reading in D'Oro 2010.
} 
closer to the reasons given by the Carnap of "Empiricism, Semantics and Ontology" than those given by Ayer's Language Truth and Logic. Bringing Collingwood in closer proximity to Carnap thus helps to counter the objection that in an attempt to make his presuppositional analysis respectable to logical positivists Collingwood unwittingly ended up conceding too much to logical positivism (Beaney 2001:118 and 2005:45ff). Collingwood (just like Carnap) would endorse this principle only in a highly qualified way, as a heuristic principle of empirical investigation, and thus as a presupposition constitutive of empirical science rather than a universal criterion of meaning. ${ }^{9}$ Metaphysical questions, for Collingwood, are unanswerable rather than simply hard to answer because they are external questions about the presuppositions which establish the criteria for making true/false claims. Logical positivists simply assumed that the criteria for meaningfulness applicable within one form of enquiry are universally applicable in all explanatory contexts because they prioritized the explanatory framework of the natural sciences. But in doing this they also fell foul of the selfundermining objection: "Is the verificationist principle an empirical proposition? Is it analytic?" If it is neither, then it fails to pass its own test for meaningfulness. According to the self-undermining objection, the principle is self-undermining because it is not a (verifiable) proposition. Logical empiricists construed the principle as a universal criterion of meaning and as a result they struggled to accommodate the principle of verification within their version of the Humean fork; Carnap and Collingwood side-step the objection by construing the principle as a criterion of meaning that is constitutive of empirical investigation.

For Collingwood the principle of verification would be vulnerable to the self-refutation objection if it were a proposition, but it is not if the principle in question is construed as a presupposition. For presuppositions are never advanced as knowledge claims. What the metaphysician propounds, for Collingwood, is not the proposition (for example) that "causes (qua handles) exist or are real" but rather this proposition: that "causes (qua handles) exist is presupposed in the practical sciences of nature". The metaphysician makes no higher-level knowledge claim. For the task of metaphysics is not to advance knowledge, in the manner of the first-order scientist, but to advance our understanding of the presuppositions on which our knowledge rests. As Collingwood put it in An Essay on Philosophical Method, philosophy

does not, like exact or empirical science, bring us to know things of which we were simply ignorant, but brings us to know in a different way things which we already knew in some way... (Collingwood 1933: 161)

Collingwood's logic of question and answer is thus not a new kind of logic alongside deductive and inductive logic. ${ }^{10}$ Its goal is not to generate new empirical knowledge by means of inductive

\footnotetext{
${ }^{9}$ The account of Collingwood's relation to logical positivism provided here differs in some important respects from other readings of Collingwood which see an Essay on Metaphysics as making far too many concessions to logical positivism. This view is articulated in Beaney 2005. For a critique of this, see D'Oro 2014. Reading An Essay on Metaphysics as espousing an internal/external distinction along the lines of Carnap also lends support to the view that in An Essay on Metaphysics Collingwood defended a form of explanatory contextualism rather than espousing a form of historical relativism that is absent in his earlier work. For a more sympathetic reading of the logic of question and answer, see D'Oro 2014 and 2002 and Martin 1998.

${ }^{10}$ For a discussion of the logic of question and answer see Belnap and Steel 1976.
} 
inferences, or expand our repertoire of a priori truths by means of deductive inferences, but to make explicit the forms of inference though which first-order knowledge is gained.

There clearly are strong points of contact between Collingwood's absolute presuppositions and Carnapian frameworks. Carnap, as we have seen, introduced frameworks to offer a solution to the problem that empiricists encounter with abstract entities. How can empirically minded scientists make use of mathematics with a clear conscience? They can do so, Carnap argued, by switching to the "numbers" framework if this is pragmatically useful to their investigation. Though Collingwood's goal was hardly that of enabling empirical scientists to use the language of abstract entities, he too was aware that the absolute presuppositions which govern different forms of inquiry criss-cross one another and that the practitioners of a science will often need to wear a different hat or, as Carnap might put it, switch from one framework to another. Doctors will acknowledge that whilst they can prevent malaria they cannot prevent human beings from ultimately dying, any more than astronomers can alter the orbits of the planets. To the extent that they acknowledge this they also acknowledge that there is a sense in which the term "cause" has a meaning which is strictly speaking banned by the framework in which they operate (qua doctors). The metaontological distinction between the theoretical and the practical sciences of nature, therefore, will not neatly map onto the kind of explanations which one finds in medicine and in physics. But the fact a doctor must concede that there are patients his medicine cannot fix does not entail that there is no distinction between the meanings that the term "cause" has in different explanatory contexts. Earthquakes and tsunamis will be mentioned in history books, not because historians assume that natural phenomena, like coups d'état or revolutions, should be explained teleologically by appealing to motives and purposes, but because reality is a complexly woven pattern. An historian will work on evidence that is passed on by forensic archaeologists whose carbon dating techniques belong to the natural rather than the human sciences. It is precisely the task of the philosopher to tease the differently coloured threads out of the complexly woven explanatory tissue. The philosophical distinction between the absolute presuppositions which govern forms of enquiries will inevitably be abstractions from the tightly knit web of explanations which co-exist in practice and it is therefore unlikely that there will be a very precise match between academic departments/disciplines in universities and the forms of enquiries which are made possible by the absolute presuppositions the metaphysician uncovers. In reality we may find a forensic archaeologist dating fragments of pots by using the same methods with which a palaeontologist dates dinosaur bones, working side by side with a hermeneutically oriented archaeologist seeking for answers to teleological questions. Indeed the forensic and hermeneutically oriented archaeologist may be one and the same person asking questions which are underpinned by one set of absolute presuppositions on one occasion and by a different set on another. The goal of philosophical clarification is not to sanitize all historical textbooks from explanations which are not of a strictly teleological nature. But the fact that the distinction between absolute presuppositions is an abstraction from the complex explanatory tissue does not entail there is no value in the philosopher's attempt to single out the differently coloured threads for the sake of achieving greater intellectual clarity.

There clearly are also significant differences between the Carnap of "Empiricism, Semantic and Ontology" and the Collingwood of An Essay on Metaphysics which have been ignored here. Collingwood saw the investigation of ontological questions internal to forms of enquiries as the only form that metaphysics could take in order to thrive and was happy to give the name of 
"metaphysics" to an investigation into the absolute presuppositions which structure our knowledge. He also believed the value of philosophical enquiry to lie in a form of meta-level conceptual clarification. Carnap, by contrast, remained wedded to the empirical framework and even if he conceded that one could switch to non-factual frameworks for pragmatic reasons, he would not have been eager to embrace metaphysics, even as construed by Collingwood. Yet it is clear from this discussion that the "isms" in idealism and pragmatism should not be allowed to congeal into mutually exclusive ideologies with no points of contact. For while there is certainly some value in classifying philosophers into pragmatists and idealists, much as there is in classifying them into rationalists and empiricists, there is also a need to treat these classifications with a pinch of salt. For the devil, as always, is in the detail and on closer inspection an idealist such as R.G. Collingwood turns out to have considerably more in common with philosophers of a quizzical than of a curious cast of mind.

\section{REFERENCES}

Ayer, A. J. [1936] 1990. Language, Truth and Logic, London: Penguin Books. First published by Victor Gollancz 1936.

Beaney, M. 2005. Collingwood's Conception of Presuppositional Analysis. Collingwood and British Idealism Studies 11(2): 41-114.

Beaney, M. 2001. Collingwood's Critique of Analytic Philosophy. Collingwood and British Idealism Studies 8: 99-122.

Belnap, N.D. and Steel T.B. 1976. The Logic of Question and Answer, New Haven and London: Yale University Press.

Carnap, R. 1950. Empiricism, Semantics and Ontology. Revue Internationale de Philosophie 4 (2):2040. Reprinted in Talisse, R. B and Aikin S.F. (eds.) 2011. The Pragmatism Reader: From Pierce Through the Present, Princeton and Oxford: Princeton University Press.

Carus, A.W. 1999. Carnap, Syntax and Truth. In J. Peregrin (ed.) Truth and its Nature (If Any), Dordrecht: Kluwer, pp. 15-35.

Chalmers, D., Manley, D. and Wasserman R. (eds.) 2009. Metametaphysics, Oxford and New York: Oxford Clarendon Press.

Collingwood, R.G. [1933]2005. An Essay on Philosophical Method, (revised edition with an introduction by James Connelly and Giuseppina D'Oro). Oxford University Press (originally Oxford: Clarendon Press, 1933.

Collingwood, R.G. [1940] 1998. An Essay on Metaphysics (revised edition with an introduction by R. Martin). Oxford University Press (originally Oxford: Clarendon Press, 1940).

Creath, R. 2011. Logical Empricism. Stanford Encyclopaedia of Philosophy.

D'Oro, G. 2002. Collingwood and the Metaphysics of Experience. London and New York: Routledge 
D'Oro, G. 2010. The Myth of Collingwood's Historicism. Inquiry 53(6): 627-641.

D'Oro, G. 2012. Reasons and Causes: the Philosophical Battle and the Metaphilosophical War. Australasian Journal of Philosophy 90(2): 207-221.

D'Oro, G. 2014. The Logocentric Predicament and the Logic of Question and Answer. In A. Skodo (ed.) Other Logics: Historical and Philosophical Alternatives to Formal Logic in the History of Thought and Contemporary Philosophy. Leiden and Boston: Brill, pp. 221-234.

Dray, W.H. 1957. Laws and Explanation in History. London: Oxford University Press.

Dray, W.H. 1963. The Historical Explanation of Actions Reconsidered. In S. Hook (ed.) Philosophy and History. New York: New York University Press, 1963.

Eklund, M. 2013. Carnap's Metaontology. Nous 47(2): 229-249.

Eklund, M. (forthcoming). Carnap's Legacy for the Contemporary Metaontological Debate. In Blatti, S. \& Lapointe, S. (eds.) Ontology after Carnap, Oxford: Oxford University Press.

Friedman, M. 2007. Carnap's Revolution in Philosophy. In M. Friedman, and R. Creath (eds.) The Cambridge Companion to Carnap, Cambridge: Cambridge University Press.

Friedman, M. 2009a. Tolerance, Intuition and Empiricism. In P. Wagner (ed.) Carnap's Logical Syntax of Language, Basingstoke: Palgrave Macmillan, pp. 236-249.

Friedman, M. 2009b. Einstein, Kant, and the Relativized A Priori. In M. Bibtol, P. Kerszberg and J. Petitot, (eds.) Constituting Objectivity: Transcendental Perspectives on Modern Physics. The Western Ontario Series in Philosophy of Science 74. Springer Netherlands, pp. 253-267.

Martin, R. 1998. Editor's Introduction in Collingwood's An Essay on Metaphysics 1998.

Pinkard, T.P. 1994. Hegel's Phenomenology: The Sociality of Reason, Cambridge: Cambridge University Press.

Pippin, R.B. 1989. Hegel's Idealism: The Satisfactions of Self-Consciousness, Cambridge: Cambridge University Press.

Price, H. 2009. Metaphysics after Carnap: The Ghost Who Walks? In Chalmers, D., Manley, D. and Wasserman R. (eds.) Metametaphysics, Oxford and New York: Oxford Clarendon Press, pp. 320-347.

Rorty, R. 1982. The Consequences of Pragmatism, Minneaopolis: University of Minnesota Press.

Wagner, P. Introduction. In P. Wagner (ed.) Carnap's Logical Syntax of Language, Basingstoke: Palgrave Macmillan, pp. 1-52.

Yablo, S. and Gallois, A. 1998. Does Ontology Rest on a Mistake? Aristotelian Society Supplementary Volume 72 (1):229 - 269. 